\title{
Etnografia e outras metodologias de pesquisa participativa com crianças: considerações a partir de um jogo de cartas $^{1}$
}

Míghian Danae Ferreira Nunes*

*(Universidade Internacional da Integração da Lusofonia AfroBrasileira - Unilab, IHL-Campus dos Malês, São Francisco do Conde-BA, Brasil)

*(Departamento de Música do Centro de Artes da Universidade do Estado de Santa Catarina, Florianópolis-SC, Brasil)
Resumo: Este artigo propõe um debate sobre o uso da etnografia e de outras metodologias participativas na condução de pesquisas com crianças, com base em questões que compõem um jogo de cartas. Fazer pesquisa com a participação de crianças implica encarar os desafios éticos, teóricos e metodológicos que pesquisadores enfrentam quando se dispõem a ouvir as crianças e a considerar seus pontos de vista e suas ideias. Tendo como ponto de partida essas questões, propomos um jogo de cartas colaborativo no qual os caminhos são definidos quando as chamadas "cartas-problemas" são apresentadas, seguidas pelas "cartas-palavras", que trazem "problemas" a serem enfrentados nas investigações com crianças. Os problemas sugeridos pelo jogo incluem a submissão das pesquisas aos comitês de ética, os assentimentos e os consentimentos e o reconhecimento do nosso adultocentrismo enquanto pesquisadores e propositores dos temas de pesquisas. Por fim, propomos abordar o adultocentrismo, um ponto que pode afetar a condução, análise e divulgação das pesquisas com crianças.

Palavras-chave: Etnografia. Metodologias participativas. Crianças. Estudos sociais da infância. 
INTRODUÇÃO

Fazer pesquisa com a participação de crianças implica o enfrentamento dos desafios teóricos, éticos e metodológicos que se colocam a quem se propõe ouvir seus pontos de vista e considerar suas ideias. Para pensar sobre essa questão fundante para o desenvolvimento de pesquisas com crianças e sobre elas, nas ciências sociais aplicadas ao campo da educação e da arte, criamos um jogo de cartas no intuito de fomentar o debate acerca dessas questões, e que podem acontecer tanto em workshops como em aulas e cursos para pesquisadores dessas áreas.

As questões que deram origem à criação do jogo de cartas iniciaram-se com as pesquisas realizadas por nós na Faculdade de Educação da Universidade de São Paulo (FE-USP), entre os anos de 2017 e 2018. As pesquisas, ambas em nível strictu sensu - doutorado e pós-doutorado -, foram etnografias que buscaram ouvir as crianças acerca de suas experiências na relação com outras pessoas, ambientes e materiais (NUNES, 2017; CUNHA, 2017; CUNHA, 2018; CUNHA; NUNES, 2018).

Este texto é o registro de algumas das questões que podem ser trazidas por este jogo colaborativo, que apresenta situações que foram encontradas em menor ou maior medida em nossas pesquisas, mas também naquelas que lemos e discutimos a partir de tantas outras realizadas com crianças. Ao escrever este texto, voltamos ao modelo acadêmico de divulgação científica, mas sem nos esquecer de incluir nessa divulgação aquilo que as crianças trouxeram de seus modos brincantes de ser para o processo de elaboração de nossas pesquisas. As reflexões aqui presentes poderão contribuir não apenas para o debate da pesquisa com crianças propriamente, mas também sobre questões relacionadas ao tema, como participação, ética e metodologia de pesquisa.

A partir das etnografias por nós realizadas, percebemos que as pesquisas com crianças constituem desafios para aqueles que se lançam nessa seara, e nos demos conta disso por questões que tivemos de enfrentar no desenvolvimento de nossas próprias pesquisas. Com isso, nos propusemos a desenvolver um jogo no qual várias situações problematizadoras são trazidas no formato de cartas, para serem discutidas por todos os jogadores ou para sugerirem outras situações parecidas; ao final da "partida", estes podem decidir se utilizam a etnografia ou outras metodologias participativas em suas pesquisas ou nos casos apresentados. 
Este jogo tornou-se o mote de workshops que já realizamos, até o momento, nas cidades de Salamanca (Espanha), no 6ํㅡㄹ Congresso Ibero-Americano em Investigação Qualitativa/2nd International Symposium on Qualitative Research (jul. 2017); na cidade de Aracaju, no VII Colóquio de Pesquisa Qualitativa em Motricidade Humana: Ecomotricidade e Bem Viver (out. 2017) e em São Paulo, na Teca Oficina de Música (nov. 2017). É importante lembrar que este texto só existe porque esse mesmo workshop, com pequenas modificações, também foi realizado no 18th luaes World Congress (jul. 2018) e publicado nos Anais deste congresso (vide nota de rodapé no título). Se você está lendo este texto, já teremos no mínimo realizado quatro vezes esse mesmo trabalho, com alterações específicas para dar conta dos formatos exigidos de tempo, organização e temática de cada evento mencionado.

Além de apresentar aqui o jogo que desenvolvemos, em momentos oportunos apresentaremos análises feitas pelos participantes dos workshops em relação aos temas tratados, trazendo para o debate questões relacionadas àquelas que havíamos pensado e/ou extrapolando muitas vezes o que propusemos como problemas a serem enfrentados por nós, pesquisadores em campo. A inclusão dessas falas foi realizada não apenas porque entendemos que os diálogos feitos nesses momentos permitiram repensar tanto o formato do próprio workshop como também algumas das questões que tínhamos como investigadoras, mas também porque buscamos seguir o que aprendemos com as crianças em relação à escuta sensível (BARBIER, 1993), aquela que incorpora o que é ouvido aos debates que estão sendo realizados, pensando neles como processo. O conceito de escuta sensível é definido por René Barbier como uma atitude mediativa, em que o pesquisador deve "saber sentir o universo afetivo, imaginário e cognitivo do outro para 'compreender do interior' as atitudes e os comportamentos, o sistema de ideias, de valores, de símbolos e de mitos (ou a existencialidade interna, na nossa linguagem)" (BARBIER, 2007, p. 94). Segundo esse mesmo autor, tal escuta permite 0 entendimento e a compreensão da complexidade do real da criança (BARBIER, 1993).

Nossas inquietações em campo e no estudo dessas metodologias tornaram-se uma atividade refletida e ao mesmo tempo dinâmica com a criação desse jogo de cartas, bem ao gosto das crianças que conhecemos em nossas pesquisas. Jogar é um verbo que remete à brincadeira, quase sempre vinculada à infância ou às crianças, muito embora discordemos da ideia de que criança "só” brinca, porque compreendemos que a brincadeira está presente na vida de todas as gerações. Como linguagem, a ideia do jogo pode evocar parte da sensação 
que tivemos ao passar um longo período com as crianças; sua proposição contém a intenção de trazer para o universo acadêmico uma nova forma de enxergar situações-problema que muitas vezes são conhecidas por aqueles que fazem pesquisas, mas que não levam em conta a presença das crianças nestas.

Ao partirmos das questões éticas encontradas no desenvolvimento desses instrumentos metodológicos nas pesquisas sobre e com crianças, principalmente na etnografia, a ideia é convidar todas as pessoas que nos leem, assim como aquelas que estiveram em nossos workshops, a entrar conosco nesse jogo colaborativo. Nele, os caminhos de investigação são definidos a partir daquilo que denominamos cartas-problemas, entregues aos grupos de participantes nos workshops.

Com as cartas em mãos, os jogadores dão início ao jogo no intuito de encontrar/analisar qual metodologia mais se adequa ou se adequaria às suas investigações com crianças, sejam elas projetos em fase de construção, pesquisas em desenvolvimento ou em processo de finalização; como tivemos também a presença de professoras e coordenadoras de escolas de Educação Infantil em nossos encontros, percebemos que as atividades das rotinas nas escolas também ensejavam investigações relacionadas aos desafios propostos pelas discussões em torno das pesquisas com crianças.

É preciso assinalar que o que aqui denominamos problema não seria um "problema”, ou seja, algo que dificulta as soluções ou mesmo as impossibilita. Na perspectiva ética que defendemos, um problema é aquilo que nos mobiliza à ação, ponto disparador de uma tensão que originaria outros problemas ou respostas às situações apresentadas, ainda que de modo localizado; o problema assim, é um desafio, um convite à reflexão sobre a pesquisa. Aqui, são também as crianças que, ao nos fazer enxergar através de outras lentes que não aquelas que solicitam de nós respostas a hipóteses prontas - elas jogam com os instrumentos que possuem (NUNES, 2017) -, trazem para o debate metodológico análises acerca dos procedimentos investigativos e da própria natureza do conhecimento científico.

\section{FAZER PESQUISA COM CRIANÇAS: QUAIS TEORIAS?}

Antes de iniciarmos o jogo propriamente dito, apresentamos as teorias que fundamentaram nossas pesquisas de campo. Sentimos a necessidade de realizar esta introdução porque, ao começarmos nossa trajetória de pesquisa 
com crianças, encontrávamos poucos materiais em que aquilo que parecia ser de interesse das crianças era levado em consideração, seja na área da pedagogia, seja na da psicologia - nomeadamente áreas em que as pesquisas com crianças não são novidade. Nesse sentido, consideramos os estudos sociais da infância - com ênfase na sociologia da infância - como um dos principais campos que fundamentam nosso debate teórico. Muitos participantes em nossos encontros disseram conhecer este campo de estudos e pesquisas, o que colaborou para que as reflexões não ficassem apenas no âmbito da apresentação da teoria, mas fossem relacionadas a outras áreas em que a discussão sobre as infâncias se fazia importante e que se constituiu também como área de atuação dos participantes, incluindo os debates sobre gênero, raça, arte, educação e política, entre outras.

A concepção de infância que fundamenta nossos trabalhos é aquela expressa pelos estudos sociais da infância: a da infância como geração e das crianças como sujeitos de direitos, seres competentes com capacidade para falar em seu próprio nome. Esclarecemos, no entanto, que ao falarmos de infância e tendo em vista que pensamos também nos bebês e nas crianças pequenas, consideramos esta fala de modo ampliado, pois as crianças falam por meio de outras linguagens e com o corpo todo. Para além da fala, elas manifestam seus pontos de vista por meio de choros, gestos, movimentos, sons, grafias plásticas, cores, dramatizações, brincadeiras, e também por meio de suas participações ou recusas, pela voz e pelo silêncio (CUNHA, 2017).

As metodologias participativas, aquelas às quais nos debruçamos neste jogo, levam em consideração as discussões de Soares, Sarmento e Tomás (2005) e Alderson (2005), para quem as metodologias participativas têm se convertido em importantes ferramentas para a realização das pesquisas com crianças porque, ao serem dinâmicas, incorporam as ações das crianças às análises produzidas e trazem outras técnicas de pesquisa (SARAMAGO, 2001; MAYALL, 2005). Nos textos de Gallacher e Gallagher (2008) e Gallagher (2008) é possível pensar também a partir das eventuais críticas que os autores fazem com relação ao uso indiscriminado das metodologias participativas, apontando ainda como o estudo da etnografia pode colaborar na alteração da perspectiva sobre participação das crianças em pesquisa.

Para pensar a etnografia com crianças, lançamos mão principalmente dos estudos de Corsaro (2011) e Ferreira (2002), por entendermos que as inquietações dessas pesquisas, que já se tornaram clássicos na área da sociologia da infância, agregam questionamentos que versam desde 
a própria natureza do trabalho de pesquisadores como também temas relacionados à infância, estes encontrados em nossas pesquisas, a saber, gênero, raça, origem, pertença geográfica, arte, educação musical, política, inter/intrageracionalidade, entre tantos outros.

O jogo começa após esta breve explanação, que não nos deixa esquecer de que um dos fios condutores que tecem esse nosso trabalho, aquele que teima em aparecer a todo o tempo quando estamos em campo e que se tornou presente na própria execução dos workshops, é mesmo a ética. Falaremos um pouco sobre o tema da ética na próxima seção.

\section{AS QUESTÕES ÉTICAS}

Ética na pesquisa com crianças poderia se converter no único tema deste artigo, haja vista o longo debate que vem sendo produzido com relação ao tema, que engloba questões como proteção e participação (ALDERSON, 2005; SOARES; SARMENTO; TOMÁS, 2005). Nas cartas-problemas, o tema da ética sempre surge nas situações vividas nas pesquisas de campo por ser, ele mesmo, uma problemática que também traz várias outras, a saber, aquelas relativas ao consentimento e ao assentimento, autoria e divulgação.

Como exemplo, escolhemos aqui tratar de uma situação com a qual tivemos contato durante a divulgação de uma de nossas oficinas, aquela que desenvolvemos na Teca Oficina de Música, em São Paulo (SP); a situação nos permite ilustrar que o debate sobre a pesquisa com crianças pode renovar o debate sobre ética na pesquisa com seres humanos nas ciências humanas (NUNES, 2017). Ao entrar em contato conosco para solicitar a divulgação da oficina em redes sociais, a direção da escola perguntou-nos, inicialmente, se tínhamos fotografias das crianças com as quais estivemos à época da pesquisa; dispúnhamos de fotografias não apenas das crianças partícipes das nossas pesquisas, mas também de outras tantas, visto que na época trabalhávamos com crianças em espaços educativos. Além dessas fotos, dispúnhamos de fotos artísticas com crianças, feitas por amigos fotógrafos que se dispuseram a ceder os direitos de imagem para uso da divulgação. Ao conversarmos sobre esse pedido, deparamos com um problema ético: as crianças haviam escolhido divulgar a oficina quando participaram das fotos? Ou, outra questão: elas ao menos foram perguntadas se queriam ser fotografadas?

Esses questionamentos suscitaram reflexões acerca do uso de fotografias de 
crianças nas pesquisas acadêmicas, em banners, folhetos para divulgação de eventos e instituições, entre outros; será que esses registros levavam em consideração o consentimento das crianças para serem realizados? Entendemos que uma ética que se ocupa apenas dos documentos descritos na legislação vigente compreende que o consentimento deve partir dos responsáveis legais pelas crianças, mas, em muitas das vezes, nada mais é feito. A pergunta que não queremos deixar calar é: esta ética tem cuidado das crianças que são exibidas em imagens? Ela não deveria, neste momento, extrapolar a burocracia que a configura a partir da proteção para reivindicar uma ética responsiva (RIBES, 2015) e que zela pelo interesse das crianças?

Mesmo antes da criação do jogo e das oficinas que realizamos, tínhamos em mente que imagens de crianças chamariam muito mais atenção para a inscrição em nossos workshops do que um desenho copiado de algum sítio da internet; acreditamos também que este é o motivo pelo qual muitas pessoas incluem fotos de crianças para ilustrar o que dizem ou o que querem afirmar, algo que Hart (1992) chama de “decoração", na escada que elaborou para falar sobre a participação das crianças nas sociedades ocidentais. Ainda assim, optamos por dizer não ao pedido por entender que, se queríamos falar sobre ética na pesquisa com crianças, era necessário enfrentar o problema quando ele também nos capturava. Assim, introduzimos nossa oficina na Teca Oficina de Música abordando o problema da imagem, o que gerou certo desconcerto em algumas pessoas do grupo que, talvez, por nunca terem pensado sobre o tema, podem ter realizado tal ação sem nem terem se dado conta da opinião das crianças sobre o uso de suas imagens.

Outra questão relativa à ética na pesquisa com crianças é a da necessidade de seus assentimentos, pois, ao pensarmos nelas como sujeitos das pesquisas ou mesmo como copesquisadoras, é fundamental ter delas essa aprovação. A ideia de que basta ter o consentimento dos pais e da direção das instituições para realizar pesquisa com crianças talvez desconheça que na legislação sobre ética em pesquisas com seres humanos no Brasil (Resolução no 510, de 7 de abril de 2016), apesar de as crianças ainda serem vistas como vulneráveis, esta prevê o assentimento esclarecido delas, termo no qual exprimem sua aceitação ou recusa em participar das pesquisas. Este é fator primordial em pesquisas dessa natureza, pois não basta apenas o consentimento dos pais, porque as crianças são capazes de responder por elas mesmas. Para Alderson (2005, p. 424), “a pesquisa social pode contribuir para o extenso debate sobre o consentimento das crianças, ao fornecer provas da competência das crianças em sua vida cotidiana e em pesquisas". Segundo Barbosa (2014, p. 244), 
Redefinir os códigos éticos, passando de uma versão moralizadora de pesquisa para uma ética de pesquisa com as crianças é uma tarefa geracional que precisamos enfrentar porque a ciência não só constata mas produz compreensão e transformação nos modos de produzir infâncias, as culturas infantis, e afirmar o empoderamento das crianças.

Existem mais duas questões que pensamos serem problemáticas do ponto de vista da ética, e que são aquelas relativas à autoria e à divulgação das pesquisas. Como equilibrar os direitos que as crianças têm à proteção, por exemplo, no uso de dados que possam lhes acarretar algum constrangimento ao tornar públicas as pesquisas? Esses são pontos que abordaremos ao final deste texto, ao tratarmos do poder adulto nas relações com as crianças, e que se revelam também na condução das pesquisas de que elas participam.

3. Metodologias de PESQUiSA COM CRIANÇAS: QUeSTÕes A PARTIR DE UM JOGO DE CARTAS

Para iniciar o jogo, apresentamos aos participantes aquilo que nomeamos como cartas-problemas: são elas que levam os pesquisadores às reflexões sobre a pertinência da escolha da etnografia ou da opção por outra metodologia participativa, combinando por vezes mais de uma situaçãoproblema, por exemplo, cartas que trazem a temática da entrada em campo e da autoria. Outras cartas, com informações complementares, que nomeamos como cartas-palavras, podem trazer, por exemplo, informações sobre a idade do grupo de crianças e/ou jovens, os conceitos tratados na situação, o contexto da pesquisa, e podem ou não ser escolhidas pelos jogadores. O conjunto completo oferece elementos para mergulharmos no jogo. Três ou mais cartas-palavras, a depender do tempo dos workshops, podem ser acopladas à carta-problema e, com exemplos práticos, o grupo pode decidir coletivamente o que fazer em cada situação proposta pelas cartas principais e pelas complementares.

Os desafios para a realização dessas pesquisas, além das questões relacionadas à própria natureza do trabalho científico com crianças idade, preferências, relações de poder entre crianças e adultos - são bons disparadores para nos aproximarmos de situações corriqueiras às investigações, situações essas que são experimentadas na qualidade de jogo, conferindo uma dinamicidade na qual a ludicidade se alia ao enfrentamento das situações-problema, em um jogo em que todos saem ganhando, com as trocas de ideias e saberes relativos às metodologias qualitativas, com foco na etnografia, nas pesquisas com crianças. 
Como exemplo da proposta pensada e construída para oficinas - o jogo de cartas -, trazemos aqui quatro delas, que propõem situações relacionadas a diferentes momentos do desenvolvimento de pesquisas com crianças. A partir dessas cartas, podem emergir questões que serão encontradas na condução delas próprias e que suscitam discussões necessárias sobre a metodologia.

Uma das discussões é a que é apresentada na carta-problema (Figura 1) a seguir, que propõe um debate sobre os termos livres e esclarecidos de consentimento e de assentimento. Esta questão do assentimento e do consentimento já foi tratada na seção anterior e aqui queremos pensar de modo mais incisivo sobre o assentimento. Vejamos a questão proposta pela carta:

Figura 1 - Carta-problema utilizada no workshop

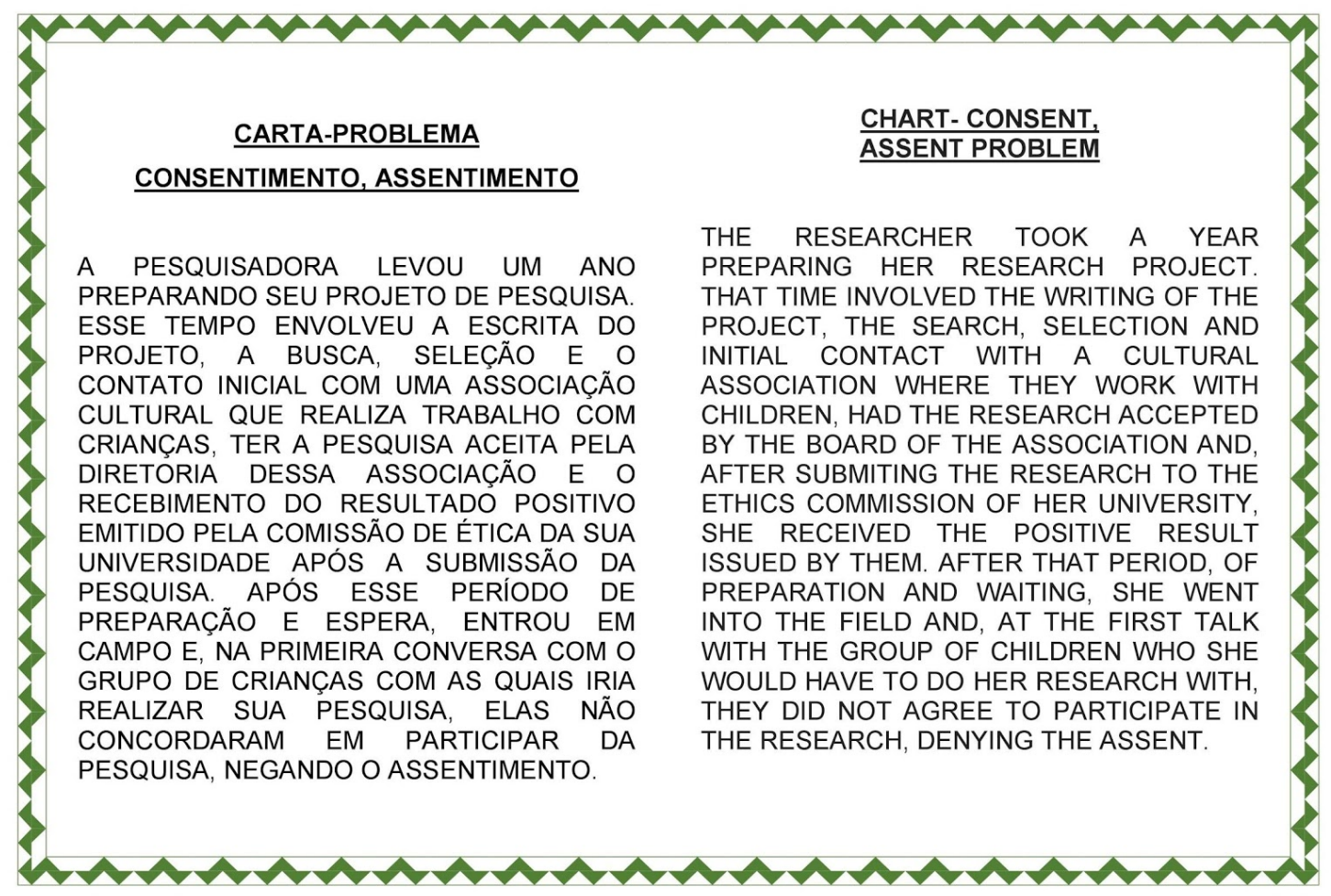

Fonte: Cunha e Nunes (2017).

Sabemos que o problema trazido por essa carta aborda uma situação extrema, mas que pode acontecer, principalmente se os pesquisadores forem iniciantes no desenvolvimento de pesquisas com crianças porque, para além das questões teóricas, tocamos no aspecto humano, visto que não basta entrarmos em contato com os grupos de crianças com as quais pretendemos desenvolver nossas pesquisas. Entendemos que é preciso ir além desse contato inicial e estabelecer com elas uma relação de confiança mútua que 
possibilite uma convivência mais alongada e que seja respeitosa dos tempos das crianças que, com alguma frequência, nos mostram pequenas recusas, silêncios e alguma indisposição para interagir conosco, ações essas que por vezes não são levadas em consideração no decorrer do trabalho acadêmico, seja porque nós mesmos não dispomos de tempo para tal, seja porque não aprendemos, ao ouvir os silêncios e as recusas, a incorporar essas atitudes ao longo da investigação como dados importantes para as pesquisas.

As discussões suscitadas por essa situação se potencializam quando entregamos a carta-palavra relacionada (Figura 2) com os termos "consentimento" e "assentimento", ensejando discussões sobre o papel muitas vezes moralizador dos comitês de ética nas pesquisas ou ainda sobre o viés biocentrista destes. A discussão pode ainda se enveredar para pensarmos sobre o momento para a apresentação e assinatura dos assentimentos pelas crianças. Nesse ponto, entendemos que deve ser levada em consideração a compreensão das crianças sobre os significados dos termos livres e esclarecidos, que devem sempre ser vistos como documentos que fazem parte de um trabalho investigativo em processo. Entre o que é estabelecido como exigência pelos comitês de ética e a realidade da pesquisa, colocamos ênfase na relação estabelecida entre pesquisadores e crianças e o vínculo construído no percurso da investigação.

Figura 2 - Carta-palavra relacionada utilizada no workshop

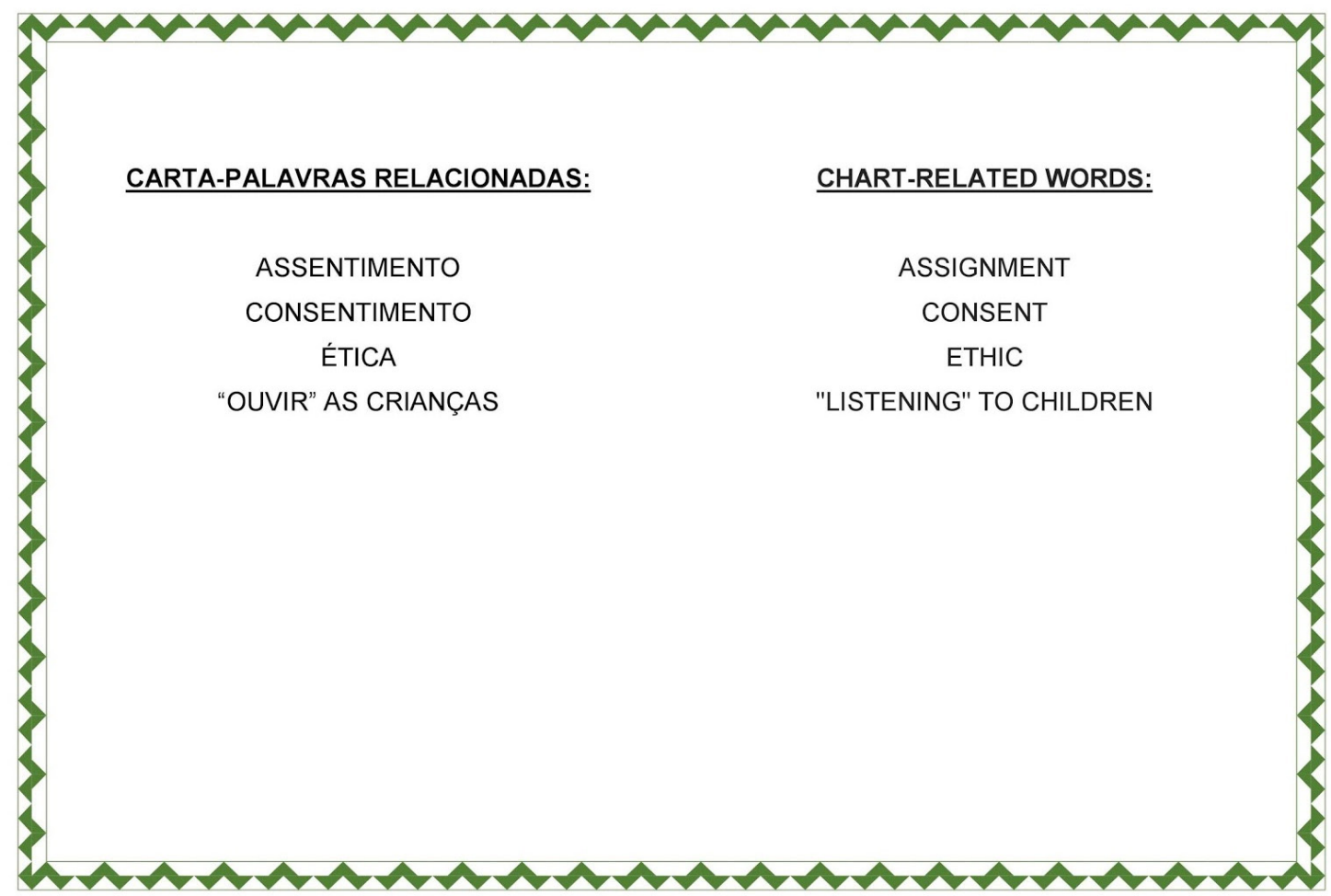

Fonte: Cunha e Nunes (2017). 
O caso extremo mostrado por essa carta-problema e os conceitos que constam da carta-palavra nos mostram como as pesquisas podem ficar impactadas com a negativa das crianças. As recusas, porém, podem acontecer não apenas no momento da assinatura dos termos de assentimento, mas também em pequenas “doses" ao longo do desenvolvimento das investigações, lembrando-nos quanto é preciso que os pesquisadores sejam sensíveis e preparados para "ouvir" as crianças, do modo a que já nos referimos anteriormente neste texto. Para nós, parece ser aqui de fundamental importância o acompanhamento dos orientadores e/ou de uma rede de suporte a esse tipo de estudo, por exemplo, dos membros de grupos de pesquisa que compartilham e discutem suas investigações e que se propõem a pensar juntos os caminhos possíveis, como uma rede de colaboração.

Aqueles com mais longa experiência no desenvolvimento de pesquisas etnográficas e/ou participativas com crianças constituem, a nosso ver, uma rede importante de apoio para a prevenção de possíveis problemas dessa natureza. Esta análise foi levantada em uma de nossas oficinas ao percebermos que muitas das perguntas realizadas por pesquisadores em nível de mestrado possuíam demandas que diziam respeito à orientação acadêmica inicial ou mesmo àquilo que poderíamos chamar aqui de maturidade intelectual, fortalecida também pela participação dessas redes acadêmicas de colaboração e orientação; vale aqui ressaltar que o termo maturidade não é qualidade apenas de quem é adulto, mas sim de toda pessoa que “matura” algo, o que inclui as crianças, em áreas da vida às quais elas podem ter mais experiência que um adulto.

A segunda carta-problema (Figura 3) que trazemos como exemplo para este artigo coloca a discussão sobre a divulgação ou o que muitos pesquisadores chamam de "devolução" para as pessoas partícipes da pesquisa sobre os resultados destas. Quando as pesquisas são realizadas com crianças pequenas ou bem pequenas, esta questão nos instiga a pensar formas de realizar tal ação, visto que as temáticas e o interesse de realizar pesquisa com crianças vêm dos adultos, e esse fato requer pensar modos alternativos de falar com elas sobre os resultados. 0 que cabe contar e o que não faz sentido para as crianças nesse caso? 
Figura 3 - Carta-problema utilizada no workshop

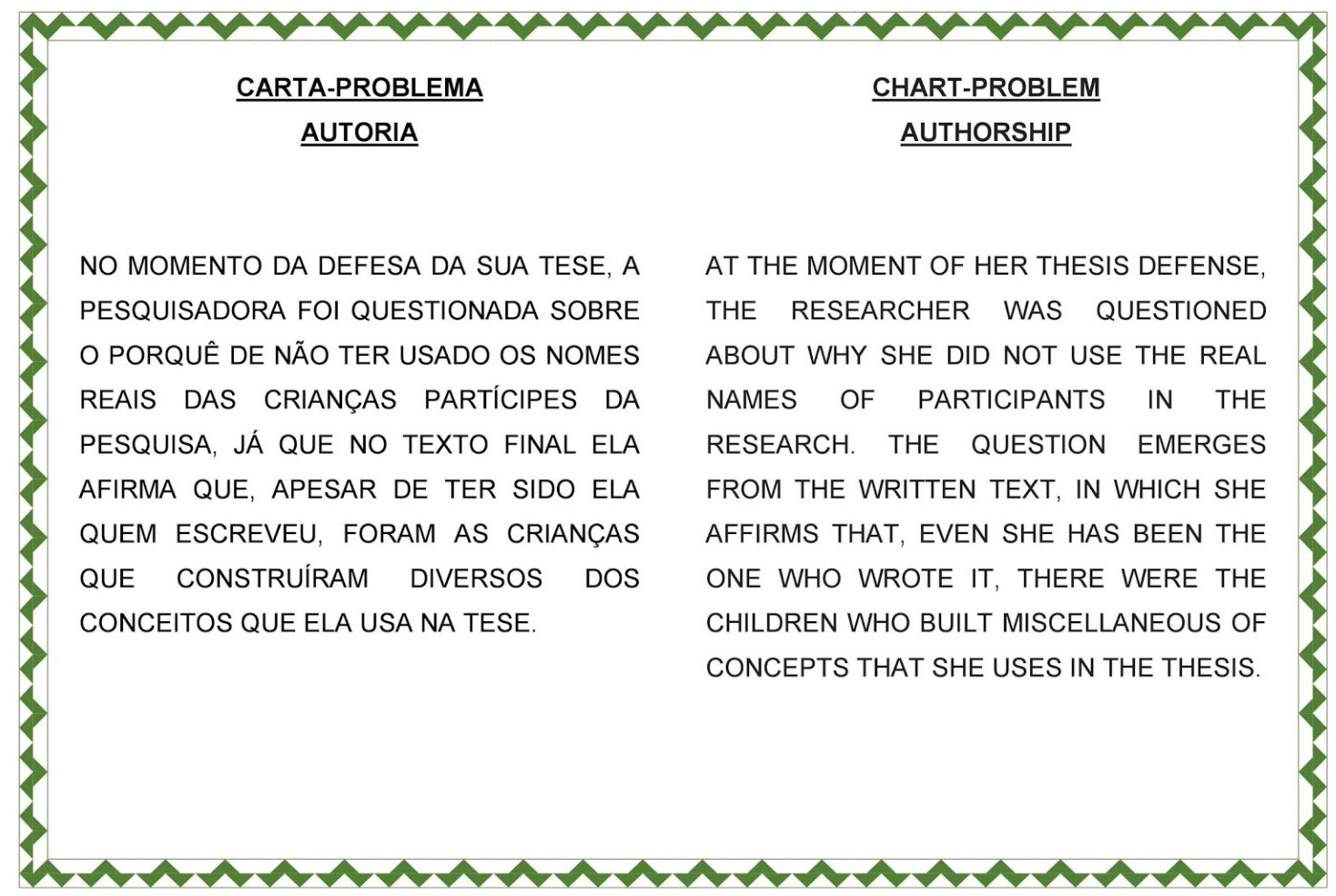

Fonte: Cunha e Nunes (2017).

No momento em que o debate sobre essa questão estiver aquecido, mostramos aos jogadores a carta-palavra relacionada a esta situação (Figura 4), trazendo mais informações sobre o contexto, a idade das crianças e os conceitos que emergem de tais debates:

Figura 4 - Carta-palavra utilizada no workshop

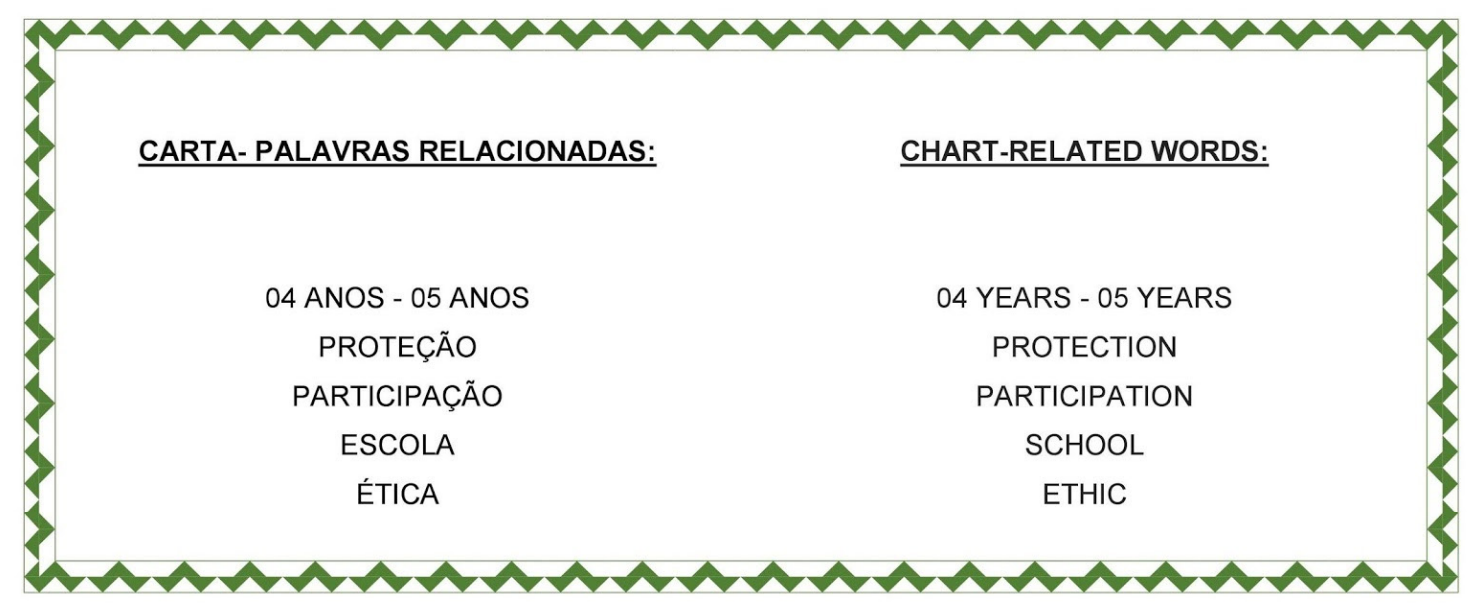

Fonte: Cunha e Nunes (2017). 
Além das cartas que aqui trouxemos como exemplo, mais cartas com temáticas representativas de outros momentos do desenrolar das investigações podem ser apresentadas nas oficinas e também em cursos, e estas proporcionaram e podem proporcionar debates instigantes. Isso tem nos mostrado que a ideia de abordar as metodologias qualitativas na condução de pesquisas com crianças por meio de um jogo de cartas é profícuo e, na opinião dos jogadores, permite o compartilhamento de incertezas e de buscas dos possíveis caminhos a serem tomados em face das situações encontradas.

\section{COMO O ADULTOCENTRISMO IMPACTA A PESQUISA COM CRIANÇAS?}

Após a discussão sobre os temas apresentados na exposição teórica e no jogo de cartas, no momento final, na avaliação dos encontros, temos discutido de que forma o adultocentrismo - considerado um dos obstáculos a se enfrentar na pesquisa com crianças (FERREIRA, 2002) - pode impactar as análises e a divulgação desse tipo de investigação.

Tematizar o adultocentrismo é debater sobre o poder adulto na relação com crianças e, caso que nos interessa neste artigo, discutir com os jogadores como isso afeta o desenvolvimento de pesquisas com crianças. Da definição dos temas de pesquisa, passando pela elaboração dos termos de assentimento esclarecido, pelo cuidado na entrada no campo, pela consideração pelos seus pontos de vista, pela aceitação das suas recusas, pela revelação ou não de seus nomes verdadeiros, pela decisão sobre quais dados revelar e quais deixar de fora são fatores que buscam respeitar as crianças e jovens e suas realidades de vida (seus direitos também à proteção). Além disso, essas discussões envolvem pensar sobre a escrita do trabalho e o melhor modo de proceder quanto à sua devolução para as pessoas partícipes da pesquisa, até chegar o momento da sua divulgação.

Em todas essas etapas de investigação, entendemos que precisamos enfrentar nosso adultocentrismo e refletir sobre como ele opera em nossas análises sobre nossa relação com as crianças. Seja por acreditar que "falamos por elas”, seja para, de modo desequilibrado, tentar imprimir à sua participação um nível de responsabilidade que sua presença não alcança, devido ao lugar social que ocupam na produção de conhecimento acadêmico, debater os efeitos do adultocentrismo nas pesquisas com crianças é assunto urgente.

Consideramos, portanto, ser este um dos grandes desafios porque, mesmo com o arcabouço teórico fundado nos estudos sociais da infância e com 0 apoio de escritos sobre etnografia aqui mencionados, o adultocentrismo emerge da nossa relação com as crianças; isso ocorre porque, muitas vezes, 
as técnicas de pesquisa que utilizamos no campo continuam a reproduzir modelos positivistas (“sujeito”-“objeto”) mesmo em pesquisas qualitativas, deixando a desejar no que tange a refletir sobre o poder presente na relação vertical que é estabelecida entre o pesquisador e as demais pessoas partícipes da pesquisa.

Este debate, assim, renova a discussão sobre a participação de seres humanos nas pesquisas acadêmicas que já vem sendo realizada pelos comitês de ética brasileiros; as crianças nos convocam a repensar se e como nosso poder de adulto dentro do campo tem sido usado, demonstrando como, em sendo um obstáculo, acaba por reduzir em alguma medida as contribuições que as relações entre adultos e crianças podem trazer aos temas que pesquisamos. Ao combater o adultocentrismo, podemos enxergar, com as crianças, caminhos para aprendermos a construir relações mais horizontais com os grupos com os quais nos relacionamos, pondo a descoberto, sempre que possível - ou, como imaginamos, quase sempre imprescindível, evidenciar os caminhos pelos quais o adultocentrismo pode nos levar em nossas formulações de problema de pesquisa e em nossas análises.

\section{CONSIDERAÇÕES FINAIS}

Fazer pesquisa com crianças nos põe diante de questões que demandam analisar a própria natureza da pesquisa científica, já que nos fazem refletir sobre como seria possível escutar as vozes das crianças nas pesquisas com elas realizadas, mesmo depois das adequações aos modelos de investigação vigentes nas universidades. Entendemos que esta profícua discussão precisa ser iniciada, sob pena de incorrermos em equívocos com relação às escolhas feitas na pesquisa com crianças, equívocos esses que podem resultar no apagamento das crianças a partir daquilo que elas podem oferecer de mais potente para as áreas do conhecimento aqui elencadas, a saber, suas presenças e novos pontos de vista sobre todos os temas, principalmente aqueles que lhes interessam e que incidem sobre suas vidas.

A partir desta nova perspectiva, o que pensam e sentem as crianças, suas ideias e saberes emergem e revelam modos distintos de compreensão do mundo. Acreditamos que debater sobre todas as questões que trouxemos, tendo o jogo de cartas como um elemento que traz situações reais vividas no desenrolar de pesquisas com crianças, nos propicia compartilhar não apenas as incertezas, mas também nos permite pensar coletivamente sobre as alternativas possíveis com o objetivo de encontrarmos o melhor caminho para o desenvolvimento de pesquisas com crianças. 


\section{Play with me? ethnography and other qualitative research with children}

Abstract: This article proposes a debate on the use of ethnography and other participatory methodologies in conducting research with children, based on issues that make up a card game. Conducting research that involves children's participation implies addressing the ethical, theoretical and methodological challenges that researchers face when they are willing to listen to children's points of view and ideas. Taking these questions as a starting point, we propose a collaborative card game in which the paths are defined as when the so-called "problem cards" are presented, followed by "words cards", that brings "problems" to be faced by in investigations with children. Problems suggested by this game include submission of research to ethics committees, assents and consents and the recognition of our adultcentrism as researchers and owners of research themes. Finally, we propose to approach adultcentrism, which is a question that can affect the conduct, analysis and dissemination of researches with children.

Keywords: Ethnography. Participatory methodologies. Children. Social studies of childhood. 


\section{Etnografía y otras metodologías de investigación participativa con niños: consideraciones a partir de un juego de cartas}

Resumen: Este artículo propone un debate sobre el uso de la etnografía y de otras metodologías participativas en la realización de investigaciones con niños, considerando cuestiones que componen un juego de cartas. Desarrollar investigación con la participación de niños implica enfrentrarse a desafíos éticos, teóricos y metodológicos por los cuales tienen que pasar los investigadores cuando se disponen a escuchar los niños bien como a considerar sus puntos de vista e ideas. Basándose en estas cuestiones, hemos propuesto un juego de cartas colaborativo en el que los caminos son definidos cuando las llamadas "cartas-problemas" son presentadas, seguidas por las "cartas-palabras", que traen "problemas" a ser enfrentados en las investigaciones con niños. Los problemas propuestos por el juego inlcuyen la sumisión de las investigaciones a los comités de ética, las aprobaciones y los consentimientos y el reconocimiento de nuestro adultocentrismo como investigadores y proponentes de los temas de investigación. Por último, proponemos abordar el adultocentrismo, un punto que puede tener consecuencias en la conducción, análisis y divulgación de las investigaciones con niños.

Palabras-clave: Etnografía. Metodologías participativas. Niños. Estudios sociales de la niñez. 


\section{REFERÊNCIAS}

ALDERSON, Priscilla. As crianças como pesquisadoras: os efeitos dos direitos de participação sobre a metodologia de pesquisa. Educ. Soc. [on-line], v. 26, n. 91, p. 419-442, 2005. Disponível em: 〈http://dx.doi.org/10.1590/S010173302005000200007>. Acesso em: 25 mar. 2019.

BARBIER, René. A escuta sensível em educação. Cadernos Anped, UFMG, n. 5, p. 187-216, 1993.

A pesquisa-ação. Brasília: Liber Livro, 2007.

BARBOSA, Maria Carmem Silveira. A ética na pesquisa etnográfica com crianças: primeiras problematizações. Práxis Educativa, Ponta Grossa, v. 9, n. 1, p. 235-245, jan./jun. 2014. Disponível em: 〈http://www.revistas2uepg.br/ index.php/praxiseducativa>. Acesso em: 25 mar. 2019.

BRASIL. Ministério da Saúde. Conselho Nacional de Saúde. Resolução no 510, de 7 de abril de 2016. Disponível em: 〈http://bvsms.saude.gov.br/bvs/ saudelegis/cns/2016/res0510_07_04_2016.html〉. Acesso em: 25 mar. 2019.

CORSARO, William. Sociologia da infância. Porto Alegre: Artmed, 2011.

CUNHA, Sandra Mara da. Crianças e jovens na congada de Santa Efigênia: aprendizagens e relações intergeracionais. 2018. Relatório de Pesquisa (Pósdoutorado)-Faculdade de Educação, Universidade de São Paulo, São Paulo, 2018.

. Pesquisa com crianças: implicações teóricas, éticas e metodológicas.

In: CONGRESO IBERO-AMERICANO EN INVESTIGACIÓN CUALITATIVA, 6./ INTERNATIONAL SYMPOSIUM ON QUALITATIVE RESEARCH, 2., 2017, Salamanca. Atas, Investigación Cualitativa en Ciencias Sociales, v. 3, p. 7782, 2017. Disponível em: 〈https://proceedings.ciaiq.org/index.php/ciaiq2017/ article/view/1142〉. Acesso em: 25 mar. 2019.

; NUNES, Míghian Danae Ferreira. Play with me? ethnography and other qualitative research with children. In: IUAES WORLD CONGRESS, 18., 2018, Florianópolis. Anais... Florianópolis, 2018. p. 5609-5622. Disponível em: 〈https://www.pt.iuaes2018.org/conteudo/view?ID_CONTEUDO=766〉. Acesso em: 25 mar. 2019.

FERREIRA, Manuela. A gente aqui o que gosta mais é de brincar com os outros meninos!: as crianças como actores sociais e a (re)organização social 
do grupo de pares no quotidiano de um jardim de infância. 2002. Tese (Doutorado)-Faculdade de Psicologia e Ciências da Educação, Universidade do Porto, Porto, 2002. Disponível em: 〈https://repositorio-aberto.up.pt/ handle/10216/19509>. Acesso em: 25 mar. 2019.

GALLACHER, Lesley-Anne; GALLAGHER, Michael. Methodological immaturity in childhood research? Thinking through 'participatory methods'. Childhood, n.15, 2008. Disponível em: 〈https://www.researchgate.net/publication/42797830_ Methodological_Immaturity_in_Childhood_Research_Thinking_through_ participatory_methods\%27〉. Acesso em: 25 mar. 2019.

GALLAGHER, Michael. 'Power is not an evil': rethinking power in participatory methods. Children's Geographies, n. 6, v. 2, p. 137-150, 2008.

HART, Roger. Children's participation: from tokenism to citizenship. Unicef: International Child Development Centre, 1992. Disponível em: 〈https://www. unicef-irc.org/publications/pdf/childrens_participation.pdf». Acesso em: 25 mar. 2019.

MAYALL, Berry. Conversas com crianças. Trabalhando com problemas geracionais. In: CHRISTENSEN, Pia; JAMES, Allison (Org.). Investigação com crianças: perspectivas e práticas. Porto: Edições Escola Superior de Educação de Paula Frassinetti, 2005. p. 123-141.

NUNES, Míghian Danae Ferreira. Mandingas da infância: as culturas das crianças pequenas na escola municipal Malê Debalê, em Salvador (BA). Tese (Doutorado)-Programa de Pós-graduação da Faculdade de Educação da Universidade de São Paulo, FE-USP, São Paulo, 2017. Disponível em: 〈http:// www.teses.usp.br/teses/disponiveis/48/48134/tde-05122017-130043/pt-br. php〉. Acesso em: 25 mar. 2019.

RIBES, Rita. Por uma ética da responsividade: exposição de princípios para a pesquisa com crianças. Currículo sem Fronteiras, São Paulo, v. 15, n. 1, p. 50 64, jan./abr. 2015. Disponível em: 〈http://www.curriculosemfronteiras.org/ vol15iss1articles/pereira.pdf〉. Acesso em: 25 mar. 2019.

SARAMAGO, Sílvia Sara Sousa. Metodologias de pesquisa empírica com crianças. Sociologia, Problemas e Práticas [on-line], n. 35, p. 9-29, 2001. Disponível em: 〈http://sociologiapp.iscte-iul.pt/pdfs/5/52.pdf〉. Acesso em: 25 mar. 2019.

SOARES, Natália Fernandes; SARMENTO, Manuel Jacinto; TOMÁS, Catarina. 
Investigação da infância e crianças como investigadoras: metodologias participativas dos mundos sociais das crianças. Nuances, v. 12, n. 13, 2005. Disponível em: 〈http://revista.fct.unesp.br/index.php/Nuances/article/ viewFile/1678/1593〉. Acesso em: 25 mar. 2019.

\section{SOBRE AS AUTORAS}

Míghian Danae Ferreira Nunes é doutora em Educação pela Universidade de São Paulo (USP). Atua como professora da Universidade Internacional da Integração da Lusofonia Afro-Brasileira, IHL-Campus dos Malês (UNILAB, São Francisco do Conde, Bahia). E-mail: mighiandanae@unilab.edu.br

Sandra Mara da Cunha é doutora em Educação pela Universidade de São Paulo (USP). Atualmente é professora adjunta do Departamento de Música do Centro de Artes da Universidade do Estado de Santa Catarina. E-mail: sandra.cunha@udesc.br

Recebido em: janeiro de 2019

Aprovado em: março de 2019 